\title{
LQR Tuning Using AIS for Frequency Oscillation Damping
}

\author{
Muhammad Abdillah $^{1}$, Teguh Aryo Nugroho ${ }^{2}$, Herlambang Setiadi ${ }^{3}$
}

\begin{abstract}
Commonly, primary control, i.e. governor, in the generation unit had been employed to stabilize the change of frequency due to the change of electrical load during system operation. But, the drawback of the primary control was it could not return the frequency to its nominal value when the disturbance was occurred. Thus, the aim of the primary control was only stabilizing the frequency to reach its new value after there were load changes. Therefore, the LQR control is employed as a supplementary control called Load Frequency Control (LFC) to restore and keep the frequency on its nominal value after load changes occurred on the power system grid. However, since the LQR control parameters were commonly adjusted based on classical or Trial-Error Method (TEM), it was incapable of obtaining good dynamic performance for a wide range of operating conditions and various load change scenarios. To overcome this problem, this paper proposed an Artificial Immune System (AIS) via clonal selection to automatically adjust the weighting matrices, $Q$ and $R$, of $L Q R$ related to various system operating conditions changes. The efficacy of the proposed control scheme was tested on a two-area power system network. The obtained simulation results have shown that the proposed method could reduce the settling time and the overshoot of frequency oscillation, which is better than conventional LQR optimal control and without LQR optimal control.
\end{abstract}

Keyword-Governor, LQR, LFC, AIS.

\section{INTRODUCTION}

The stability of the electric power system is still a serious concern today. There are transient disruptions (such as net break or short circuit) and dynamic disruptions (around the work point) for electric power system operation. The second type of disturbance is caused by small load changes or often called as dynamic interference [1]-[3]. This dynamic disturbance can cause a poor system frequency fluctuations, it can even bring the system to an unstable area.

Load Frequency Control (LFC) is a system used to keep frequencies at their nominal values, because frequency fluctuations are caused by load changes. LFC has a goal that must be achieved in power system operation, especially to maintain variations in system frequency in load distribution that must be borne by each generator during power exchange process between areas to meet the needs of the scheduled load [4].

1,2 Lecturer, Department of Electrical Engineering, Faculty of Industrial Technology, Universitas Pertamina, Teuku Nyak Arief Street, Simprug, Kebayoran Lama, Jakarta 12220 (Tel.: (021) 29044308; e-mail: m.abdillah@universitaspertamina.ac.id; teguh.an@universitaspertamina.ac.id)

${ }^{3}$ Lecturer, Department of Engineering, Faculty of Vocational, Universitas Airlangga, Campus B UNAIR, Jl. Srikana 65, 60286, Surabaya, Indonesia (Tel.: (031) 5033869; email: herlambang.setiadi@vokasi.unair.ac.id)
Several studies have been conducted to improve the system performance so as to make it stable and robust due to interference using optimal control based on Linear Quadratic Regulator (LQR) have been conducted. Some of them are LQR used for various-information-policy-based switched system (informed policies) [5], to fix the performance of Doubly-Fed Induction Generator (DFIG) [6], LQR developed into the Fractional Linear Quadratic Optimal Control Problem (FLQOCP) for Caputo sense problems [7], LQR as feedback control to reduce small-signal oscillatory dynamics in the power system [8], and LQR as net power controllers, active power regulators, and voltage stabilizers in residential PV systems [9].

For several years, the Artificial Intelligence (AI) method has been used to tune control parameters to control the system adaptively when changes occur in the system, such as changes in load. For example, the AI method used to optimize LQR is Genetic Algorithm (GA). GA is utilized to tune LQR and is applied for Motion Cueing Algorithm (MCA) optimal design [10]. Another AI method such as Harmony Search Algorithm (HAS) has also been used to tune LQR parameters as feedback control on CH-47 helicopters and inverted pendulums [11]. In addition to the AI method, Artificial Immune System (AIS) is an AI method that has been widely used to solve a search for value in a complex optimization problem. This is because the operators in AIS, such as hypermutation with mutation potential, and aging are very beneficial and efficient for AIS to handle local optima problems compared to other AI methods. Some examples of optimization problems using AIS are substations placement optimisation in distribution systems [12]; energy supply optimisation in distributed electric power system net [13]; to improve cluster algorithm of a kernel-based intuitionistic fuzzy C-means [14]; solve NP-hard partition problem from combinatorial optimization problems [15]; for Computer-Aided Musical Orchestration (CAMO) aims to optimally find the right combination of musical instrument sound that perceptually close to the reference sound when played together [16]; and AIS for optimizing a very complex network design problems [17]. The LQR and AIS applications in a number of aforementioned case studies have resulted in excellent performance in solving problems of control and optimization studies. Therefore, this paper applied LQR as an additional supplementary control called as the Load Frequency Control (LFC) for a two-area electric power system. The $\mathbf{Q}$ and $\mathbf{R}$ parameters of LQR were optimized using AIS via clonal selection to improve LFC's dynamic performance by looking at changes in frequency response of areas one and two as well as variations in power changes in the interconnection network. To test the robustness and effectiveness of the proposed control scheme, a load change of 0.01 pu was given in Area 1 and the system parameters were changed. Results of the proposed method were compared with a conventional LQR optimal 
control which its $\mathbf{Q}$ and $\mathbf{R}$ parameters were obtained using the Trial Error Method (TEM) and the LFC system without using optimal control.

\section{Modeling of Proposed Systems And Methods}

A summary of the LFC model, the interconnection of twoarea electric power systems, and the theoretical basis of LQR and AIS is described in this section.

\section{A. Load Frequency Control (LFC) Model}

A diagram of LFC and Automatic Voltage Regulator (AVR) scheme installed on a synchronous generator connected to an electric power system net is shown in Fig. 1. LFC serves to keep the frequency at a nominal value/rating, while AVR serves to maintain a fixed voltage at its nominal value when an interruption occurs such as load changes during the continuation of the electric power system operation. Fluctuations in $\delta$ rotor angle and $f$ frequency value changes greatly affects the active power changes, while voltage magnitude changes affect reactive power changes. Signal errors from the $\Delta \delta$ rotor angle are corrected when there is a change in the frequency and power of the tie-line by observing changes in the $\delta$ rotor angle. Error signals of $\Delta f$ frequency and obtained tie-line $\Delta P_{\text {tie }}$ power were combined and converted into $\Delta P_{V}$ active power. A $\Delta P_{V}$ signal was transmitted to the main mover to inform the system to increase the torque. Changes in the value of the $\Delta P_{G}$ output generator depended on main mover and this condition would change the values of $\Delta f$ and $\Delta P_{\text {tie. }}$.

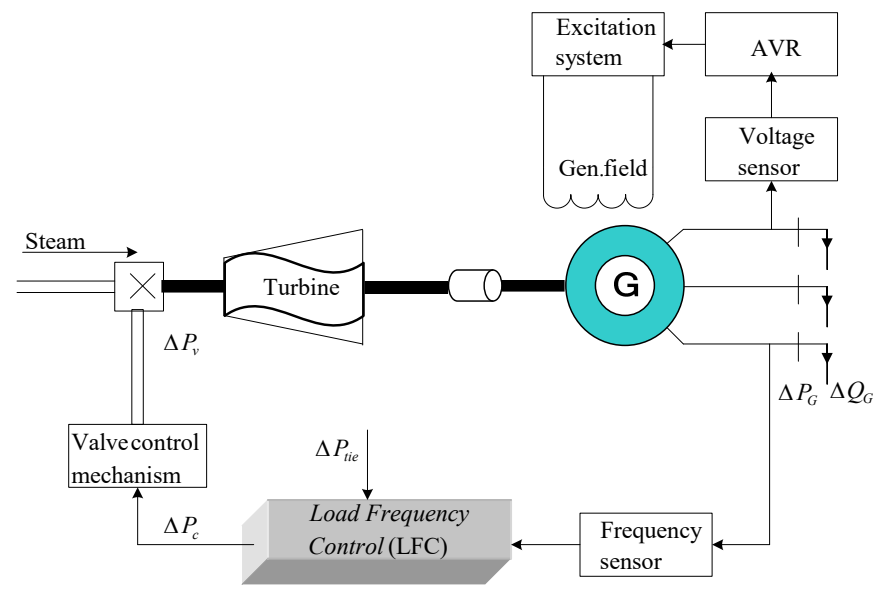

$$
\begin{array}{ll}
\Delta P_{G} & =\text { active power of the generator } \\
\Delta Q_{G} & =\text { reactive power of the generator } \Delta P_{\text {tie }}=\text { tie-line power } \\
\Delta P_{C} & =\text { speed control }
\end{array}
$$

Fig. 1 A schematic diagram of LFC and AVR installed on a synchronous generator [18].

\section{B. Configuration of Two-Area LFC}

The configuration of the two-area interconnected electric power system was connected by an $X_{\text {tie }}$ line reactance, as shown in Fig. 2. Then, Fig. 3 shows the electrical equivalent circuit of a two-area system, with each area represented by a voltage source and an equivalent reactance viewed from a tie bus. The power streaming from Area 1 to Area $2\left(P_{12}\right)$ is formulated in (1).

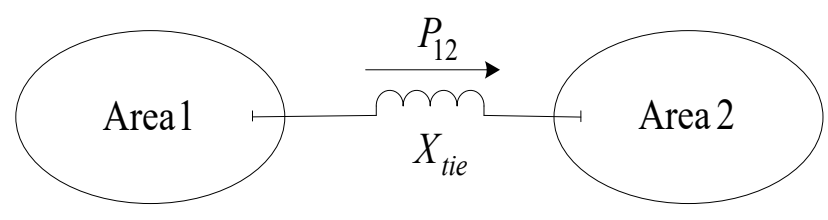

Fig. 2 A configuration of two-area interconnected electric power system.

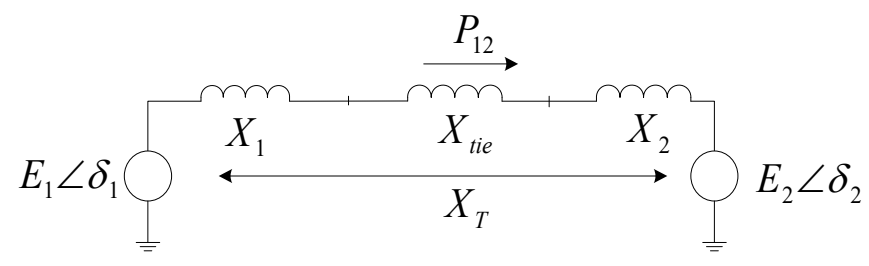

Fig. 3 Electric equivalent circuit.

$$
P_{12}=\frac{E_{1} E_{2}}{X_{T}} \sin \left(\delta_{1}-\delta_{2}\right) .
$$

Linearization regarding the operation starting point can be represented $\delta_{1}=\delta_{10}$ dan $\delta_{2}=\delta_{20}$, so that

$$
\begin{aligned}
& \Delta P_{12}=T \Delta \delta_{12} \\
& T=\frac{E_{1} E_{2}}{X_{T}} \cos \left(\delta_{1}-\delta_{2}\right)
\end{aligned}
$$

where $\Delta \delta_{12}=\Delta \delta_{1}-\Delta \delta_{2}, \delta_{1}$ and $\delta_{2}$ are the phase angles of generator areas 1 and $2, X_{T}$ is the total reactance of the transmission net, $E_{1}$ and $E_{2}$ is the generator voltage of areas 1 and 2 , and $T$ is the torque coefficient of synchronization between areas.

A linear model of the LFC block diagram in a two-area interconnected electric power system is represented in Fig. 4, while the general form of the state-space model of the system is given in (4).

$$
\begin{aligned}
& \dot{x}(t)=\mathbf{A} x(t)+\mathbf{B} u(t) \\
& y(t)=\mathbf{C} x(t)
\end{aligned}
$$

where $\mathbf{A}, \mathbf{B}$, and $\mathbf{C}$ are system matrices, inputs, and outputs; $x(t)$ is a state variable; $u(t)$ is input; and $y(t)$ is the output From Fig. 4 the obtained variables of state space function matrices, inputs, and outputs are as follows.

State variable:

$$
\begin{aligned}
x(t)= & {\left[\Delta f_{1} \Delta P_{T 1} \Delta P_{G 1} \Delta P_{C 1} \Delta P_{t i e} \Delta f_{2} \Delta P_{T 2}\right.} \\
& \left.\Delta P_{G 2} \Delta P_{C 2}\right]^{\mathrm{T}} .
\end{aligned}
$$

Input variable consists of two inputs, i.e.,

$$
u(t)=\left[\Delta P_{L 1} \Delta P_{L_{2}}\right]^{\mathrm{T}} \text {. }
$$

The observed output variable is

$$
y(t)=\left[\begin{array}{lll}
\Delta f_{1} & \Delta f_{2} \Delta & P_{\text {tie }}
\end{array}\right]^{\mathrm{T}} .
$$

Parameter data and information included in Fig. 4 are as follows.

$$
T_{T i} \quad=\text { turbine time constant of } i^{\text {th }} \text { area }
$$




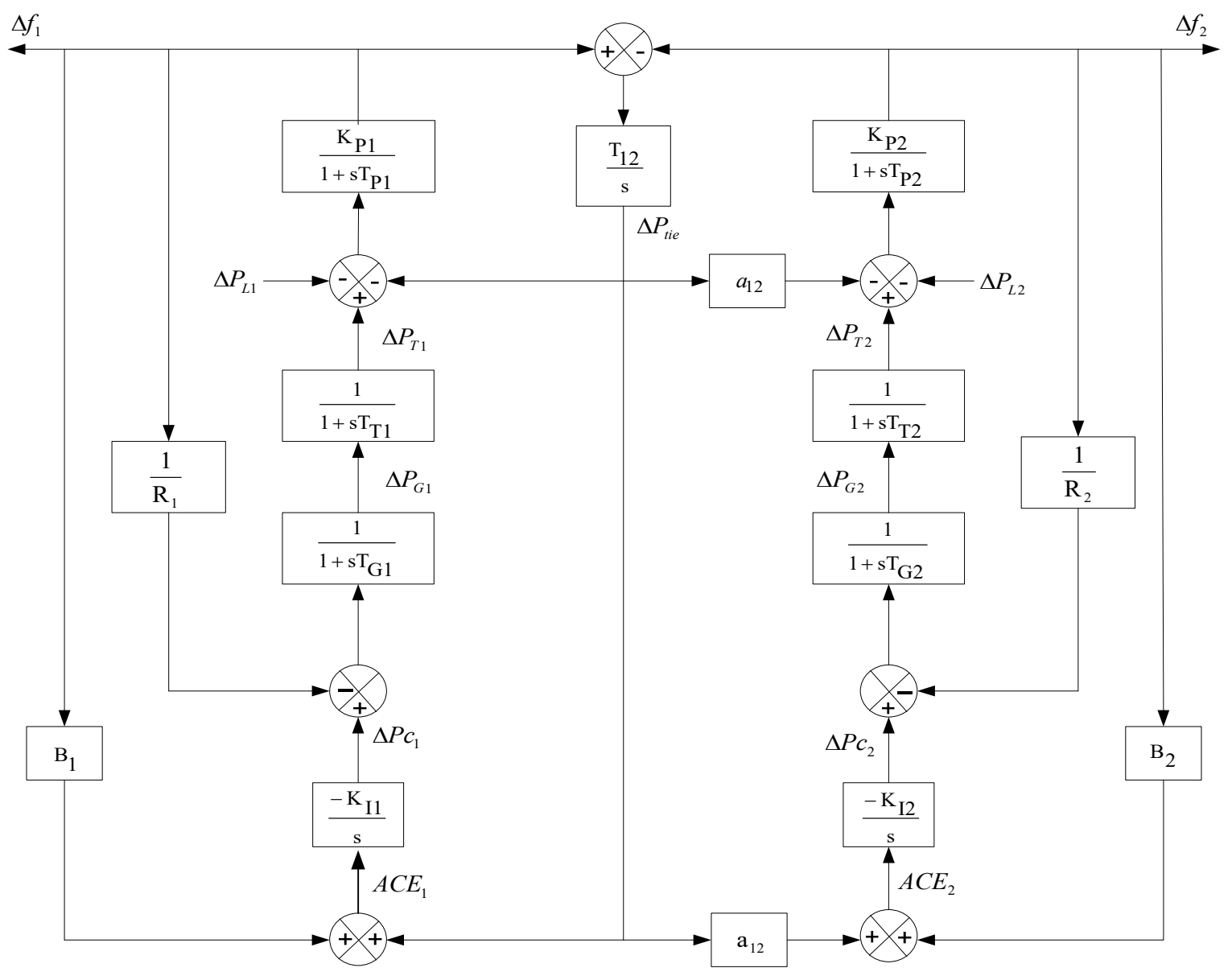

Fig. 4 A block diagram of two-area interconnected electric power system [18].

$T_{G i} \quad=$ governor time constant of $i^{\text {th }}$ area

$T_{P i} \quad=$ power system time constant of $i^{\text {th }}$ area

$K_{P i} \quad=$ power system gain of $i^{\text {th }}$ area

$T_{i j} \quad=$ synchronization coefficient

$B_{i} \quad=$ frequency bias parameter of $i^{\text {th }}$ area

$K_{i} \quad=$ integral gain of $i^{\text {th }}$ area

$\Delta f_{i} \quad=$ variations in frequency change of $i^{\text {th }}$ area

$\Delta P_{T i}=$ variations in turbine power change of $i^{\text {th }}$ area

$\Delta P_{G i}=$ variations in changes in governor valve level of $i^{\text {th }}$ area

$\Delta P_{C i}=$ variations in integral control changes of $i^{\text {th }}$ area

$\Delta P_{L i} \quad=$ variations in load power changes of $i^{\text {th }}$ area

$U_{i} \quad=$ input control of $i^{\text {th }}$ area

$\triangle A C E_{i}=$ error control of $i^{\text {th }}$ area

$\Delta P_{\text {tie }}=$ variations in tie line power changes.

The two-area interconnected electric power system in Fig. 4 are two identical generators, so they have the same system parameter, as shown in Table I.

\section{Linear Quadratic Regulator (LQR)}

Equations (4) and (5) were used to obtain a $\mathbf{K}$ gain/amplifier from the feedback control of the LQR method. Performance index of $J$ in (9) was minimized using several iterations in the optimisation process.
TABLE I

LFC PARAMETERS [18]

\begin{tabular}{|c|c|c|c|}
\hline \multicolumn{2}{|c|}{ Area 1 } & \multicolumn{2}{c|}{ Area 2 } \\
\hline $\mathrm{K}_{\mathrm{p} 1}$ & $120 \mathrm{~Hz} / \mathrm{puMW}$ & $\mathrm{K}_{\mathrm{p} 2}$ & $120 \mathrm{~Hz} / \mathrm{puMW}$ \\
\hline $\mathrm{T}_{\mathrm{g} 1}$ & $0.08 \mathrm{~s}$ & $\mathrm{~T}_{\mathrm{g} 2}$ & $0.08 \mathrm{~s}$ \\
\hline $\mathrm{T}_{\mathrm{p} 1}$ & $20 \mathrm{~s}$ & $\mathrm{~T}_{\mathrm{p} 2}$ & $20 \mathrm{~s}$ \\
\hline $\mathrm{T}_{\mathrm{T} 1}$ & $0.3 \mathrm{~s}$ & $\mathrm{~T}_{\mathrm{T} 2}$ & $0.3 \mathrm{~s}$ \\
\hline $\mathrm{R}_{\mathrm{g} 1}$ & $2.4 \mathrm{~Hz} / \mathrm{puMW}$ & $\mathrm{R}_{\mathrm{g} 2}$ & $2.4 \mathrm{~Hz} / \mathrm{puMW}$ \\
\hline $\mathrm{B}_{1}$ & $0.425 \mathrm{puMW} / \mathrm{Hz}$ & $\mathrm{B}_{2}$ & $0.425 \mathrm{puMW} / \mathrm{Hz}$ \\
\hline $\mathrm{K}_{\mathrm{i} 1}$ & 1 & $\mathrm{~K}_{\mathrm{i} 2}$ & 1 \\
\hline $\begin{array}{l}\mathrm{T}_{12}=0.545 \mathrm{puMW} \\
\mathrm{a}_{12}=-1\end{array}$ & & \\
\hline
\end{tabular}

$J\left(t_{0}\right)=\frac{1}{2} x^{T}(T) S(T) x(T)+\frac{1}{2} \int_{t_{0}}^{T}\left[\left(x^{T} \mathbf{Q} x+u^{T} \mathbf{R} u(t)\right] d t\right.$

with $S(T) \geq 0, \quad \mathbf{Q} \geq 0, \quad \mathbf{R}>0 . \quad S(T)$, as well as $\mathbf{Q}$ and $\mathbf{R}$ are symmetrical weighting matrices. Optimal control solution by minimizing $J$ in (9) uses Algebraic Riccati Equation (ARE), as shown in (10) [19].

$$
-\dot{S}=\mathbf{A}^{T} \mathbf{S}+S \mathbf{A}-S \mathbf{B R}^{-1} \mathbf{B}^{T} S+\mathbf{Q}
$$

The gain matrix/amplifier, $\mathbf{K}$, from LQR-based feedback control was obtained using (11) which was then applied as LFC on the two-area power system using (12). 


$$
\begin{aligned}
& \mathbf{K}(t)=\mathbf{R}^{-1} \mathbf{B}^{T} S(t) \\
& u(t)=-\mathbf{K}(t) x(t)
\end{aligned}
$$

\section{Artificial Immune System (AIS)}

AIS in an optimisation algorithm imitating human immune systems. In the immune system, lymphocytes play a role in helping the process of producing antibodies. Lymphocytes have two main components, namely B-lymphocytes and $\mathrm{T}$ lymphocytes. B-lymphocytes are cells produced by bone marrow and T-lymphocytes are produced by the thymus. Blymphocytes can be programmed to produce an antibody placed on the outer surface of the lymphocytes. This antibody acts as a receptor. The antibody production mechanism is regulated by using T-lymphocytes. Fig. 5 shows a clonal selection principle.

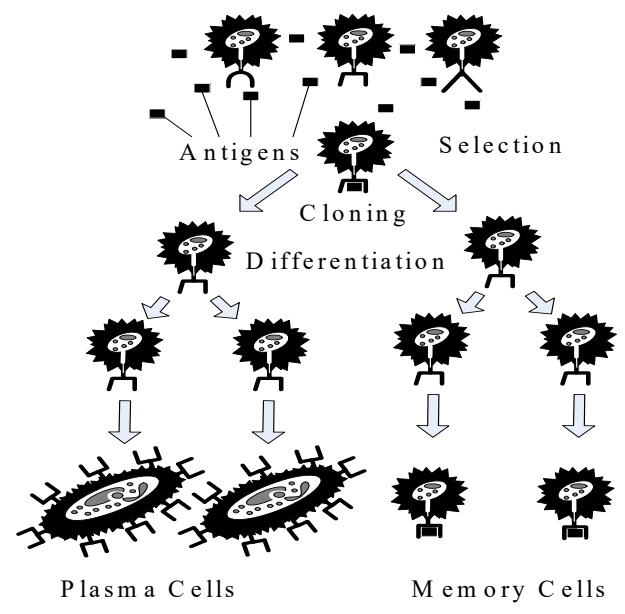

Fig. 5 Clonal selection principle [20].

The immune system can detect and eliminate foreign cells (antigens) and cancer cells. Therefore, this system can distinguish between foreign cells with their own cells. There are many types of antibodies that can be produced by the immune system. However, one antibody can only recognize and eliminate one type of antigens. The antigens recognized by antibodies are called epitopes. Epitope serves as a differentiator between one antigens with another antigen. Each antibody has a specific antigens detector called an idiotope. Lymphocytes receive trigger signals when the receptors detect antigens. This trigger signal can activate clonal proliferation to clone plasma cells. The cloning process is continued with the maturation process. In the maturation process, the mutations and hyper mutations were carried out to obtain affinity maturation. Memory cells and plasma cells were produced in an affinity maturation condition.

\section{IMPLEMENTATION OF THE PROPOSED METHOD}

In this paper, optimal LQR control was applied as an LFC to improve the system dynamic stability in a two-area power system. The LQR optimal control was designed using AIS via clonal selection. AIS via clonal selection serves as a tool to tune the weighting matrix values in the LQR optimal control, namely the $\mathbf{Q}$ matrix and the $\mathbf{R}$ matrix. Antibody structure utilized in AIS via clonal selection is shown in Fig. 6.

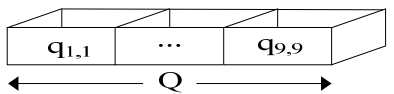

(a)

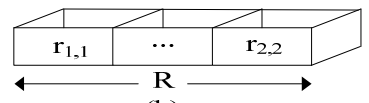

(b)

Fig. 6 Antibody structure, (a) for the $\mathbf{Q}$ matrix, (b) for the $\mathbf{R}$ matrix.

The antibody structure is divided into two parts, namely a) antibodies consisting of nine genes, it represents a $\mathbf{Q}$ weighting matrix with the element numbers depending on the number of system state variables; and b) antibodies consisting of two genes, it represents $\mathbf{R}$ weighting matrix with the element number depending on the number of system input variables.

Equation (9) is a function of a system performance index $(J)$ in the optimal LQR control and is utilized as an affinity function in the optimization process using AIS via clonal selection. Flowchart of AIS process in selecting LQR optimal control weighting matrix is shown in Fig. 7. Gain matrix/amplifier, $\mathbf{K}$, resulted from this method was utilized to control two-area power system input.

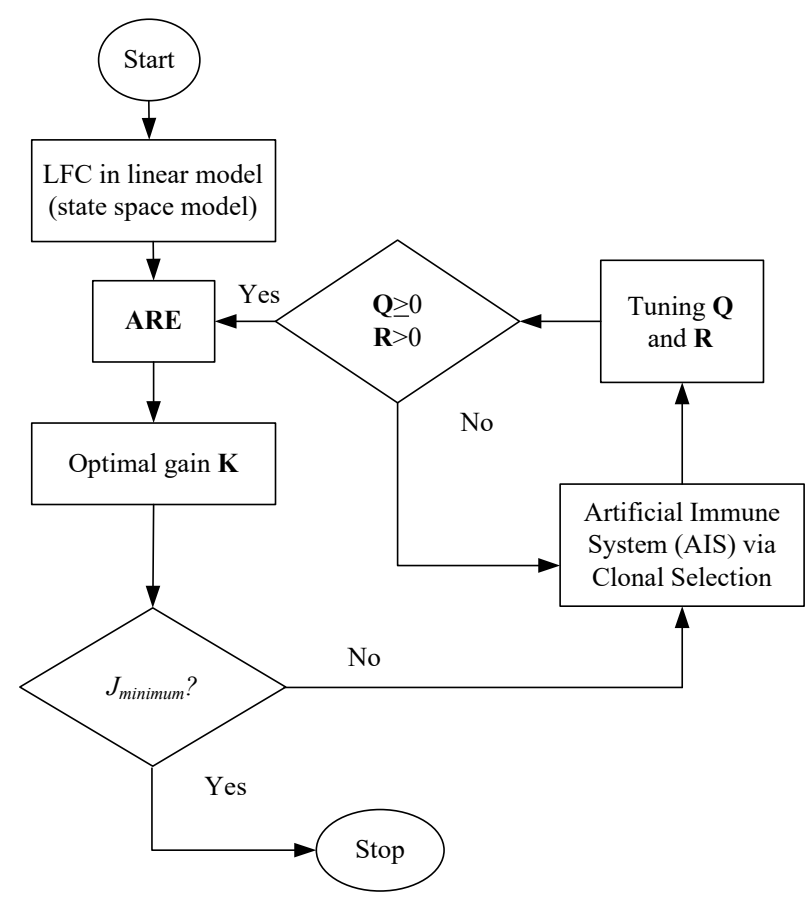

Fig. 7 Flowchart of the proposed method.

\section{Simulation Results}

All simulations in this paper were implemented in MATLAB using AMD Ryzen $72.3 \mathrm{GHz}$ and 16GB RAM memory. A system dynamic performance based on frequency changes of area 1 and area 2 as well as power changes on two-area power system net, both without using LQR optimal control, LQR with $\mathbf{Q}$ and $\mathbf{R}$ matrices obtained with TEM (LQR-TEM), and LQR with its parameters optimized using AIS (LQR-AIS) are given in this section. In this paper, case studies are divided into three studies to test the effectiveness of the proposed method. 


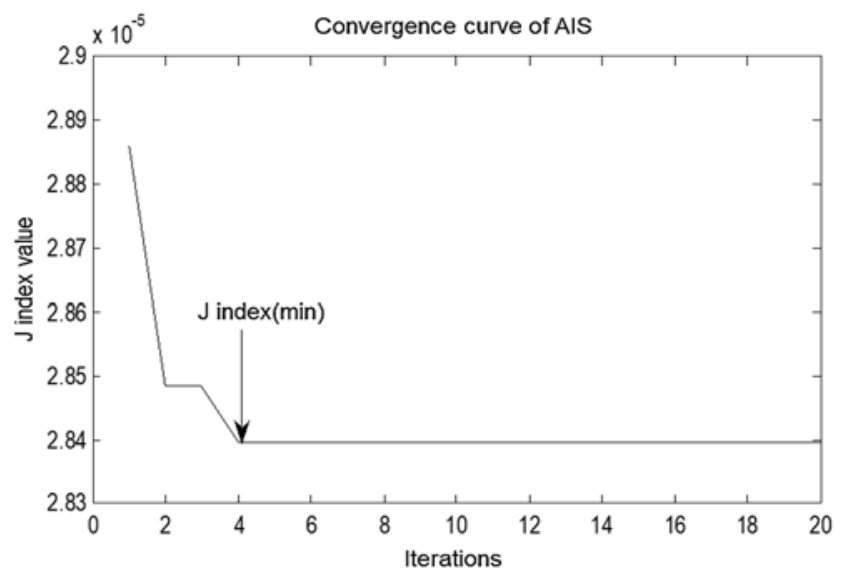

Fig. 8 AIS convergence graph for case study 1.

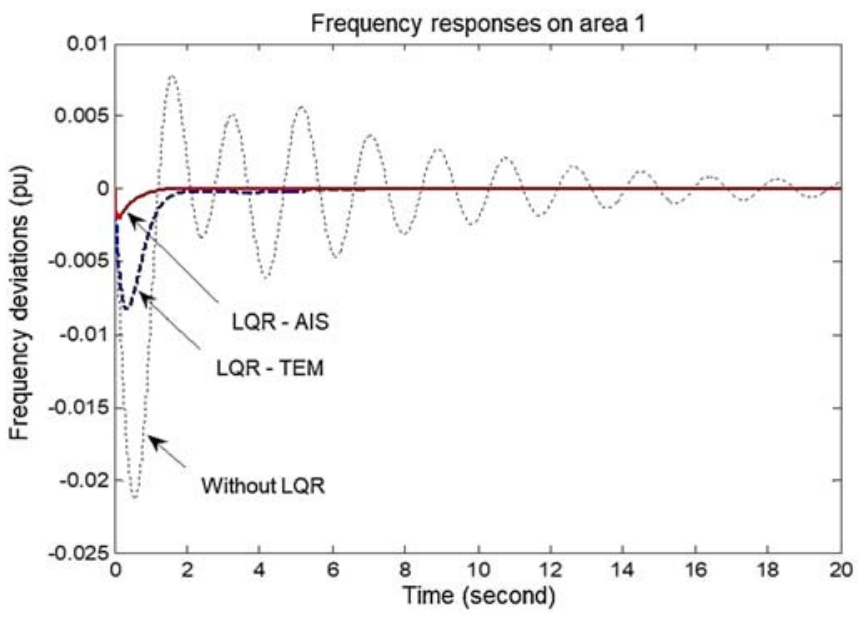

Fig. 9 Response to changes in frequency area 1 for case study 1.

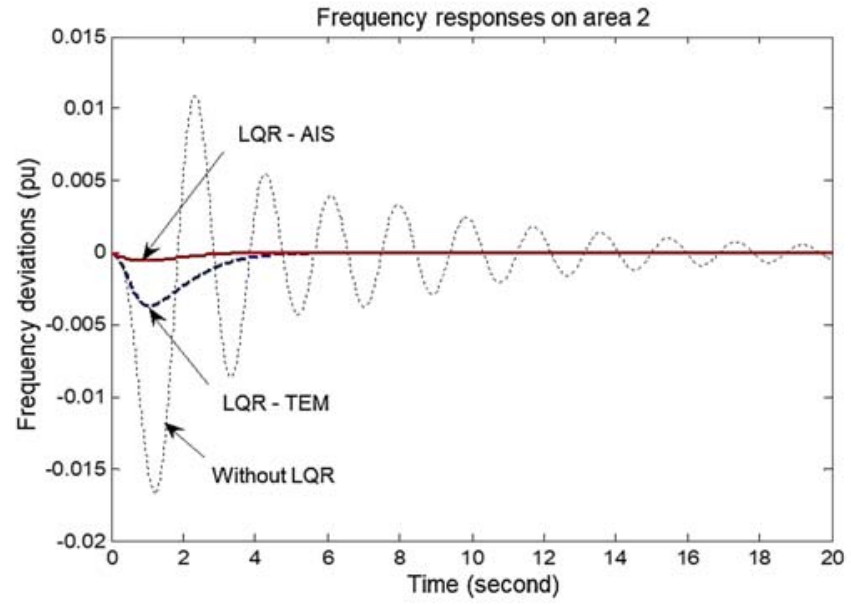

Fig. 10 Response to changes in frequency area 2 for case study 1.

\section{A. Case Study 1}

In case study 1 , the system was given input disturbance in a form of $\Delta P_{L I}$ load changes of 0.01 p.u. in area 1 . Simulation results for case study 1 are shown in Fig. 8 to Fig. 11.

Fig. 8 shows that the value of $J$ converges on the 4 th iteration with the value of $2.8388 \times 10^{-5}$. This shows that the minimum
$J$ index value converges before reaching the maximum iteration value. The number of AIS antibodies utilized in case study 1 was 15 , while the maximum number of utilized iterations was 20.

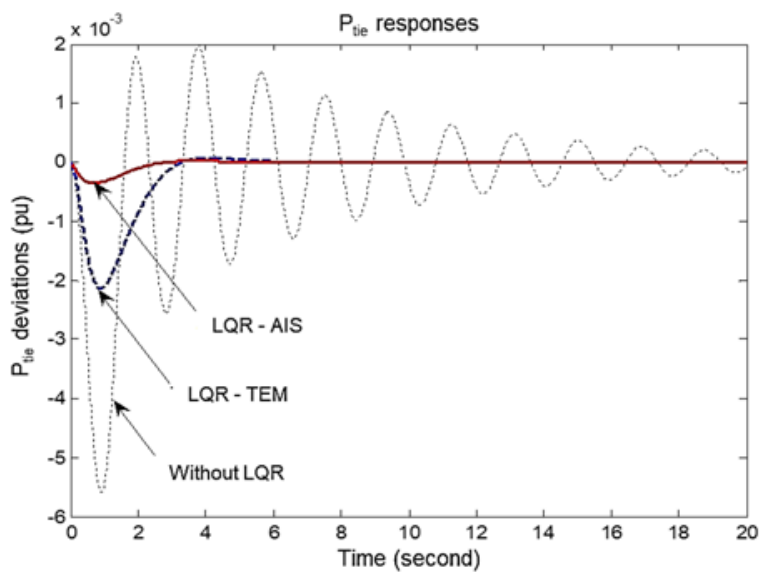

Fig. 11 Responses to $P_{t i e}$ 's power variations for the case study 1 .

The response to changes in frequency area 1 and 2 as shown in Fig. 9 and Fig. 10 shows that the best performance was obtained by LQR-AIS. Overshoot of changes in frequency of area 1 and area 2 can be well damped and it reaches steady-state after $1.31 \mathrm{~s}$ and $2.66 \mathrm{~s}$. The response to $P_{t i e}$ 's power change in Fig. 11 shows that overshoot is well damped using the LQRAIS method and it reaches steady-state after $2.69 \mathrm{~s}$. The overshoot and settling time values of Fig. 9 to Fig. 11 are shown in Table II and Table III.

TABLE II

COMPARISON OF OVERSHOOT

\begin{tabular}{|c|c|c|c|}
\hline Output & $\begin{array}{c}\text { Without LQR } \\
\text { (pu) }\end{array}$ & $\begin{array}{c}\text { LQR-TEM } \\
\text { (pu) }\end{array}$ & $\begin{array}{c}\text { LQR-AIS } \\
\text { (pu) }\end{array}$ \\
\hline$\Delta f_{1}$ & -0.0213 & -0.0082 & -0.0019 \\
\hline$\Delta f_{2}$ & -0.0167 & -0.0037 & $-5.338 \mathrm{e}-004$ \\
\hline$\Delta P_{\text {tie }}$ & -0.0056 & -0.0021 & $-3.3483 \mathrm{e}-004$ \\
\hline
\end{tabular}

TABLE III

COMPARISON OF SETTLING TIME

\begin{tabular}{|c|c|c|c|}
\hline Output & $\begin{array}{c}\text { Without LQR } \\
\text { (s) }\end{array}$ & $\begin{array}{c}\text { LQR-TEM } \\
\text { (s) }\end{array}$ & $\begin{array}{c}\text { LQR-AIS } \\
\text { (s) }\end{array}$ \\
\hline$\Delta f_{1}$ & 45.5 & 5.64 & 1.31 \\
\hline$\Delta f_{2}$ & 45.5 & 5.4 & 2.66 \\
\hline$\Delta P_{\text {tie }}$ & 37.65 & 4.92 & 2.69 \\
\hline
\end{tabular}

\section{B. Case Study 2}

For case study 2 , the system was given input of disturbance in a form of $\Delta P_{L 1}$ load change of $0.01 \mathrm{pu}$ in area 1 and all system parameters were changed to $-5 \%$. Changes in the AIS affinity convergence value, changes in frequency area 1 and 2, and changes in $P_{\text {tie }}$ power are shown in Fig. 12 to Fig. 15.

Value of $J$ reaches the minimum and converges after the $3 \mathrm{rd}$ iteration as many as $1.5628 \times 10^{-3}$, as shown in Fig. 12. This shows that the minimum $J$ value can be reached before the maximum iteration. The number of utilized antibodies was 10 , the maximum number of iterations was 16 . 


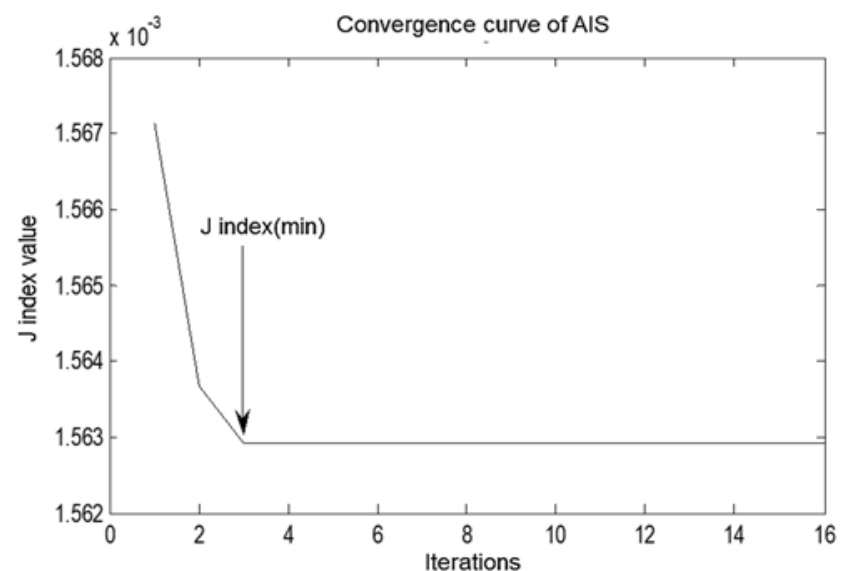

Fig. 12 AIS convergence graph for case study 2.

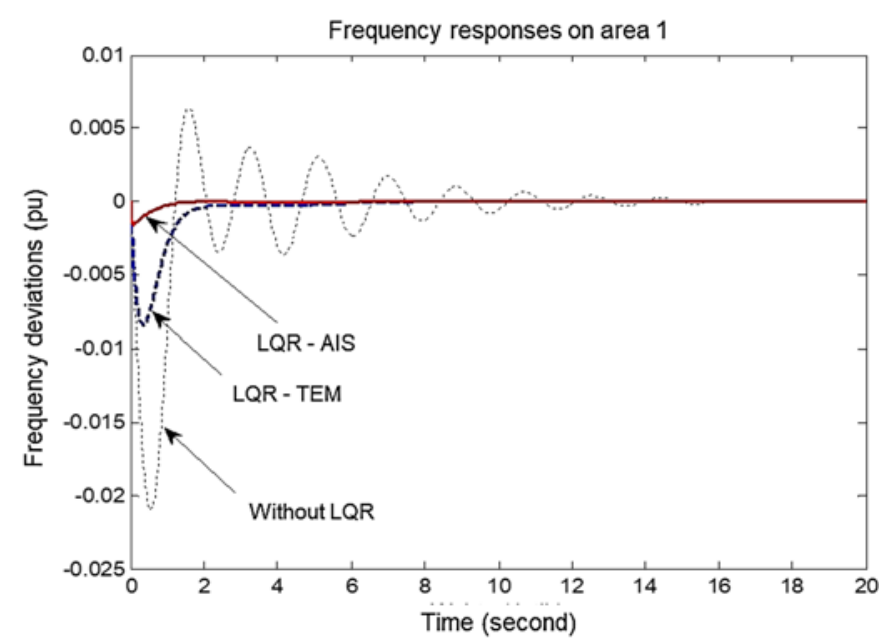

Fig. 13 Response to changes in frequency area 1 for case study 2 .

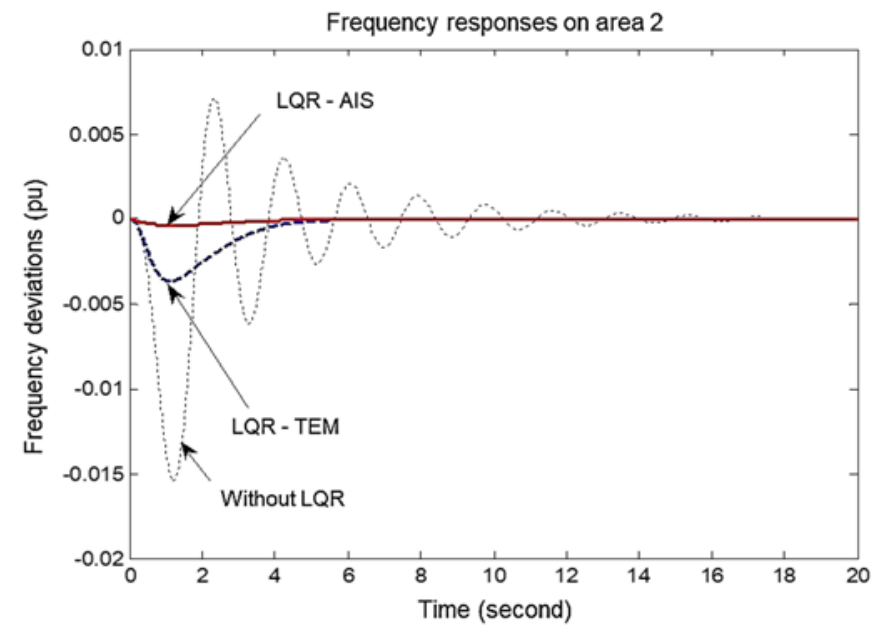

Fig. 14 Response to changes in frequency area 2 for case study 2.

The response to changes in frequency area 1 and 2, as shown in Fig. 13 and Fig. 14, shows that the smallest overshoot and settling time is obtained by using the LQR-AIS method. LQRAIS is able to dampen overshoot changes in frequency area 1 and 2, changes in $P_{\text {tie }}$ power, and reaches steady-state after 1.33 s, $2.76 \mathrm{~s}$, and $3.34 \mathrm{~s}$. The overshoot and settling time values of Fig. 13 to Fig. 15 are shown in Table IV and Table V.

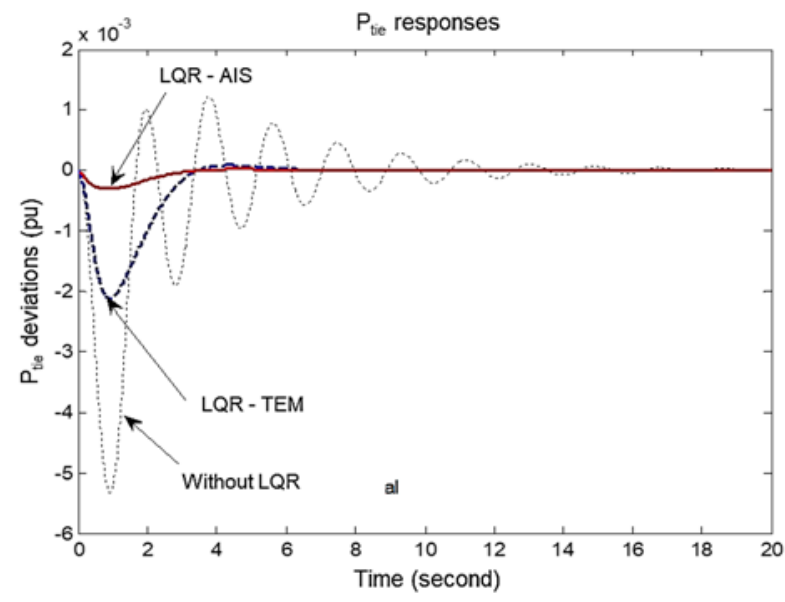

Fig. 15 Responses to to $P_{\text {tie }}$ power for case study 2 .

TABLE IV

COMPARISON OF OVERSHOOT

\begin{tabular}{|c|c|c|c|}
\hline Output & $\begin{array}{c}\text { Without LQR } \\
\text { (pu) }\end{array}$ & $\begin{array}{c}\text { LQR-TEM } \\
\text { (pu) }\end{array}$ & $\begin{array}{c}\text { LQR-AIS } \\
\text { (pu) }\end{array}$ \\
\hline$\Delta f_{1}$ & -0.0207 & -0.0083 & -0.001435 \\
\hline$\Delta f_{2}$ & -0.0154 & -0.0037 & $-3.937 \mathrm{e}-004$ \\
\hline$\Delta P_{\text {tie }}$ & -0.0053 & -0.0021 & $-3.155 \mathrm{e}-004$ \\
\hline
\end{tabular}

TABLE V

COMPARISON OF SETTLING TIME

\begin{tabular}{|c|c|c|c|}
\hline Output & $\begin{array}{c}\text { Without LQR } \\
\text { (s) }\end{array}$ & $\begin{array}{c}\text { LQR-TEM } \\
\text { (s) }\end{array}$ & $\begin{array}{c}\text { LQR-AIS } \\
\text { (s) }\end{array}$ \\
\hline$\Delta f_{1}$ & 25.75 & 6.61 & 1.33 \\
\hline$\Delta f_{2}$ & 25.75 & 5.38 & 2.76 \\
\hline$\Delta P_{\text {tie }}$ & 21.55 & 6.56 & 3.34 \\
\hline
\end{tabular}

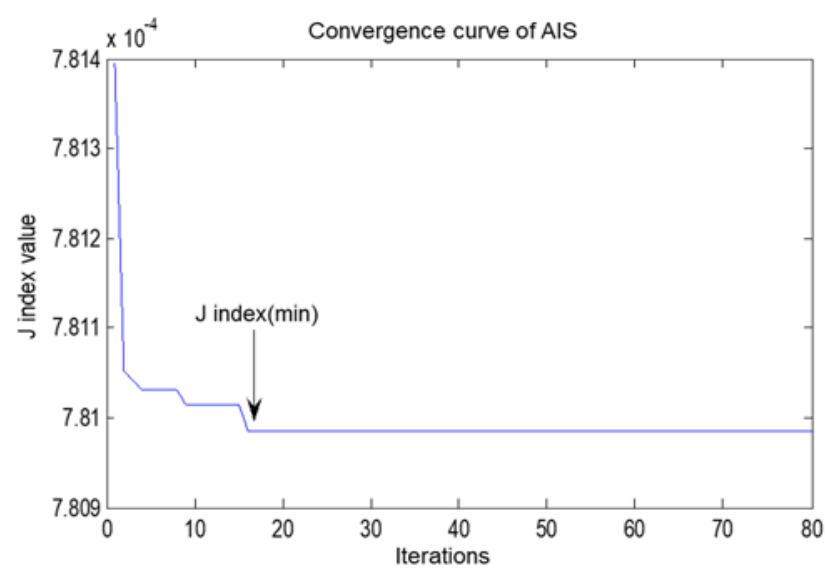

Fig. 16 AIS convergence graph for case study 3.

\section{Case Study 3}

In case study 3 , a $\Delta P_{L I}$ load change of 0.01 pu was applied to area 1 and all system parameters were changed by $+5 \%$. Fig. 16 shows that the convergence of LQR-AIS values was achieved in the 16 th generation with a $J$ value of $7.8098 \times 10^{-4}$. 
This shows that the minimum $J$ value can be achieved in the 16th generation before reaching the maximum iteration value. The number of utilized antibodies from AIS was 20, while the maximum number of iterations was 80 .

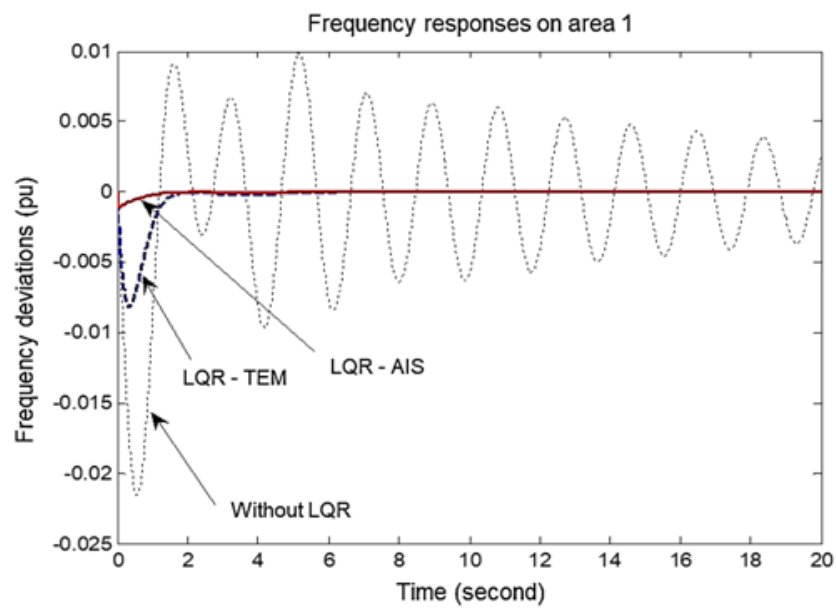

Fig. 17 Response to changes in frequency area 1 for case study 3.

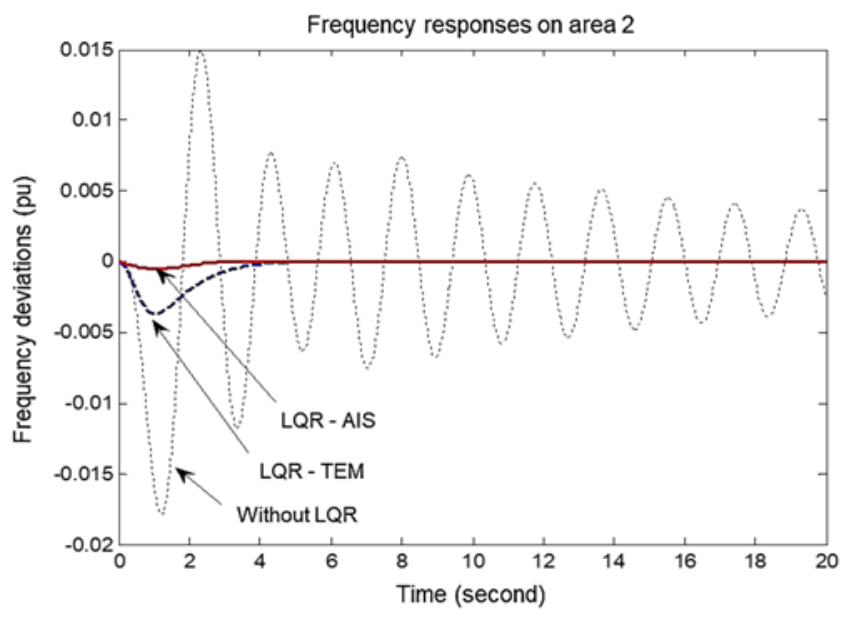

Fig. 18 Response to changes in frequency area 2 for case study 3 .

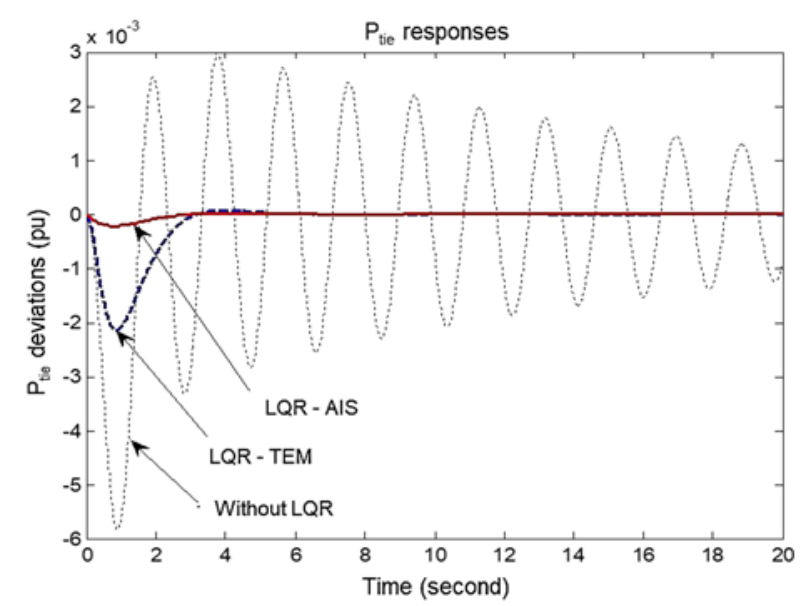

Fig. 19 Responses to $P_{\text {tie }}$ power for case study 3 .

From Fig. 17 to Fig. 19, it is shown that the response of changes in frequency areas 1 and 2 and the response of $P_{\text {tie }}$ power changes possessing a good overshoot and settling time are obtained by the LQR-AIS method. Overshoot values of changes in frequency areas 1 and 2 and changes in $P_{\text {tie }}$ power can be well damped using LQR-AIS and it reaches steady-state after $1.13 \mathrm{~s}, 2.18 \mathrm{~s}$, and $2.91 \mathrm{~s}$. The overshoot and settling time values of Fig. 17 to Fig. 19 is shown in Table VI and Table VII.

TABLE VI

COMPARISON OF OVERSHOOT

\begin{tabular}{|c|c|c|c|}
\hline Output & $\begin{array}{c}\text { Without LQR } \\
\text { (pu) }\end{array}$ & $\begin{array}{c}\text { LQR-TEM } \\
\text { (pu) }\end{array}$ & $\begin{array}{c}\text { LQR-AIS } \\
\text { (pu) }\end{array}$ \\
\hline$\Delta f_{1}$ & -0.0215 & -0.0080 & -0.001087 \\
\hline$\Delta f_{2}$ & -0.0177 & -0.0036 & $-3.948 \mathrm{e}-004$ \\
\hline$\Delta P_{\text {tie }}$ & -0.0058 & -0.0021 & $-2.168 \mathrm{e}-004$ \\
\hline
\end{tabular}

TABLE VII

COMPARISON OF SETTLING TIME

\begin{tabular}{|c|c|c|c|}
\hline Output & $\begin{array}{c}\text { Without LQR } \\
\text { (s) }\end{array}$ & $\begin{array}{c}\text { LQR-TEM } \\
\text { (s) }\end{array}$ & $\begin{array}{c}\text { LQR-AIS } \\
\text { (s) }\end{array}$ \\
\hline$\Delta f_{1}$ & 126.6 & 5.68 & 1.13 \\
\hline$\Delta f_{2}$ & 126.6 & 4.3 & 2.18 \\
\hline$\Delta P_{\text {tie }}$ & 106.5 & 5.4 & 2.91 \\
\hline
\end{tabular}

\section{CONCLUSION}

An AIS via clonal selection method to tune $\mathbf{Q}$ and $\mathbf{R}$ parameters from LQR optimal control has been proposed in this paper. According to simulation results that have been carried out for three case studies, it can be concluded that AIS via clonal selection to tune LQR parameters adaptively or called as LQR-AIS gives good results for two-area power system applications compared to trial-error and without optimal LQR control methods. LQR-AIS is able to dampen overshot of frequency changes of area 1, frequency changes of area 2 , changes of $P_{\text {tie }}$ power, and a shorter settling time to a steady state so that the dynamic performance of two-area power system is improved.

\section{REFERENCES}

[1] P.S.R. Murty, Electrical Power Systems, $1^{\text {st }}$ ed., Butterworth-Heinemann, United Kingdom: Elsevier, 2017.

[2] A. Soeprijanto, M. Abdillah, D.F.U. Putra, Mardlijah, and Rusilawati, "Power System Stabilizer Based on Interval Type 2 Fuzzy Sliding Mode Controller for Oscillation Damping on 500kV Java-Bali Electrical Power System, “J. Electrical Systems,” Special Issue 3, pp. 1-11, 2015.

[3] I.B.G. Manuaba, M. Abdillah, A. Priyadi, and M.H. Purnomo, "Coordinated Tuning of PID-based PSS and AVR Using Bacterial Foraging-PSOTVAC-DE Algorithm," Control and Intelligent Systems, Vol. 43, No. 3, pp. 1-9, 2015.

[4] S. Saxena, "Load Frequency Control Strategy via Fractional-order Controller and Reduced-order Modeling," International Journal of Electrical Power \& Energy Systems, Vol. 104, pp. 603-614, Jan. 2019.

[5] D. Antunes and W.P.M. Heemels, "Linear Quadratic Regulation of Switched Systems Using Informed Policies," IEEE Transactions on Automatic Control, Vol. 62, No. 6, pp. 2675-2688, Jun. 2017.

[6] G.P. Prajapat, N. Senroy, and I.N. Kar, "Stability Enhancement of DFIGbased Wind Turbine System Through Linear Quadratic Regulator," IET Generation, Transmission \& Distribution, Vol. 12, No. 6, pp. 1331-1338, 2018.

[7] O. Baghani, "Solving State Feedback Control of Fractional Linear Quadratic Regulator Systems Using Triangular Functions," 
Communications in Nonlinear Science and Numerical Simulation, Vol. 73, pp. 319-337, July 2019.

[8] A.K. Singh and B.C. Pal, Dynamic Estimation and Control of Power Systems, $1^{\text {st }}$ ed., Cambridge, USA: Academic Press, 2018.

[9] N. Arab, B. Kedjar, A. Javadi, and K. Al-Haddad, "A Multifunctional Single-Phase Grid-Integrated Residential Solar PV Systems Based on LQR Control," IEEE Transactions on Industry Applications, Vol. 55, No. 2, pp. 2099-2109, March 2019.

[10] H. Asadi, S. Mohamed, C.P. Lim, and S. Nahavandi, "Robust Optimal Motion Cueing Algorithm Based on the Linear Quadratic Regulator Method and a Genetic Algorithm," IEEE Transactions on Systems, Man, and Cybernetics: Systems, Vol. 47, No. 2, pp. 238-254, Feb. 2016.

[11] L.B.P. Nascimento, V.P. Pinto, and M.A.B. Amora, "Harmony Search Algorithm with Adaptive Parameters to Optimize the Linear Quadratic Regulator Design," IEEE Latin America Transactions, Vol. 16, No. 7, pp. 1862-1869, Jul. 2018.

[12] F.T.S. Silva, L.R. Araujo, and D.R.R. Penido, "Optimal Substation Placement in Distribution Systems Using Artificial Immune Systems," IEEE Latin America Transactions, Vol. 16, No. 2, pp. 505-513, Feb. 2018.

[13] T. Wakui, M. Hashiguchi, K. Sawada, and R. Yokoyama, "Two-stage Design Optimization Based on Artificial Immune System and Mixedinteger Linear Programming for Energy Supply Networks," Energy, Vol. 170, pp. 1228-1248, March 2019.
[14] W. Zang, Z. Wang, D. Jiang, and X. Liu, "A Kernel-based Intuitionistic Fuzzy C-Means Clustering Using Improved Multi-objective Immune Algorithm," IEEE Access, Vol. 7, pp. 84565-84579, June 2019.

[15] D. Corus, P.S. Oliveto, and D. Yazdan, "Artificial Immune Systems can Find Arbitrarily Good Approximations for the NP-hard Number Partitioning Problem," Artificial Intelligence, Vol. 274, pp. 180-196, September 2019.

[16] M. Caetano, A. Zacharakis, I. Barbancho, and L.J. Tardon, "Leveraging Diversity in Computer-aided Musical Orchestration with an Artificial Immune System for Multi-modal Optimization," Swarm and Evolutionary Computation, Vol. 50, pp. 1-46, Nov. 2019.

[17] I.A. Carvalho and M.A. Ribeiro, "A Node-depth Phylogenetic-based Artificial Immune System for Multi-objective Network Design Problems," Swarm and Evolutionary Computation, Vol. 50, pp. 1-52, Nov. 2019.

[18] H. Saadat, Power System Analysis, $2^{\text {nd }}$ ed., New York, USA: McGrawHill, 2004.

[19] F. Lewis, Optimal Control, Hoboken, USA: John Wiley \& Sons, Inc, 1986.

[20] L.N. de Castro and F.J. Von Zuben, "Learning and Optimization Using the Clonal Selection Principle," IEEE Transaction on Evolutionary Computation, Vol. 6, No. 3, pp. 239-251, 2002. 